and you should take advantage of the present climate of receptivity for intensive forest management. The world knows about the problem, the world understands that the forest industry is vital to Canada and Canadians everywhere are seeking a meaningful commitment to future generations. With its appeal to the notion of conservation, with its pervasive presence everywhere in Canada, with its labour intensity and with its relatively low cost - reforestation simply has to be one of the best Canadian bets around.

The selling has largely been done, the action has not yet begun.

\section{Integration of Forest and Wildlife Management ${ }^{1}$}

\section{by Ken Brynaert ${ }^{2}$}

The Honourable John Roberts in a speech to the Nova Scotia Forest Products Association, on January 29, 1982, stated - "The forest resource is Canada's most valuable natural endowment; it has more growth potential than any other sector of our economy. But we are abusing it. We have been using our forests without giving anything back and thas has got to stop."

These comments need to be put into a perspective for consideration by the reader. Forest products make up 14 percent of all manufactured goods in Canada and in 1980 Canadian exports of forest products reached 12.8 billion dollars About one million Canadians are employed in the forest products industry and over 300 communities depend on forestry for their existence. However, the warning is clear, uncontrolled exploitation, with no thought to the future, will lead to serious labour and material shortages and the effects on our environment will be irreparable.

We are already facing some of these problems in the forest sector of our economy. Local shortages of timber are emerging across the country. Why? Because until recently man thought that nature would replace the trees that were removed. The crisis facing the forest industry was aptly covered by Roy MacGregor in his article "Heritage Lost" appearing in Today Magazine, June 5 , 1982. The fact that Canada's forests have been seriously mismanaged for several decades is gradually beginning to receive the public scrutiny that it justly deserves.

The forest industry in Canada has developed over the past two centuries. Initially it provided for the needs of the colonists, and later, to utilize surplus timber, as an adjunct to clearing land. This was expanded to supply the markets of Britain and Europe, particulraly for ship building, and more

\footnotetext{
Reprinted from: International Wildlife, Sept./Oct 1982.

${ }^{2}$ Executive Vice-President, Canadian Wildlife Federation.
}

recently to satisfy the demands of the pulp and paper industry and the needs of Canada's construction industry. During this period of our history, forest management policy has been formulated largely to meet the needs and demands of the forest industry. In the last several decades, these needs and demands have been oriented to supplying the almost insatiable appetite for more wood, created by the export market, particularly for pulp and paper products.

Forest management policies have been justified on the basis of the forest industry's potential to provide employment, income and other economic benefits. Political leaders have been unduly influenced by the forest industry, permitting operators a relatively free hand in the management of forest resources within their respective timber limits. As a consequence of this, inadequate control has been maintained on the level and extent of forest utilization. Extraction has exceeded the allowable cutting limits for many years, and there is some question of whether these allowable cutting limits were ever properly ascertained and identified

It is becoming abundantly clear now that reforestation and regeneration of cut-over forest land has been totally inadequate to ensure a continuing supply of wood. Recent reports indicate that most provinces can expect to face serious shortages of harvestable timber, within the next decade, because regeneration and growth has not been maintained on about one third of the forest land subject to extraction over the past three decades. The problem probably started long before that and includes areas that were harvested fifty or sixty years ago. It is evident that we have not practiced proper rotation as a consequence of shortsighted and short-term forest management policies.

Problems related to over harvesting have been masked to some extent by the utilization of wood produced on private lands. As this source of supply declined. the impacts of inadequate management policies, and the destruction of forests by insects, fire and disease have become increasingly clear. As a consequence of mismanagement, most if not all provinces now face the prospect of having to substantially reduce forest production pending the receipt of benefits from more enlightened management. It is likely this situation will continue well into the next century.

Entirely apart from the now apparent impacts on forest production, it is also necessary to consider how forest management has affected wildlife. Wildlife management is the art of manipulating animals or their environment for the purpose of achieving certain pre-determined goals or objectives. Wildlife values contribute extensively to the economy of each province and are estimated, nationally, to be in the order of 9.5 billion annually. Much of this value comes from forest lands in the form of recreational benefits, and the goods and services bought or used in the pursuit of these activities. Included are the direct commercial benefits, taxes and licence fees and the value of meat and fish taken by anglers and hunters. In addition are the incomparable aesthetic and spiritual values realized daily by the people of Canada from coast to coast.

Wildlife management has been hampered, and adversely effected, by an inability to influence forest management practises on public lands and virtually no authority to intervene on private lands. The result has been a general deterioration in wild life habitat, due in no small measure to policies narrowly oriented to wood production. Clear cutting of large areas, destruction of winter range, emphasis on monoculture of preferred commercial species, and the failure to recognize and consider other forest based values have all contributed to this situation. We are now faced with the prospects of extended spraying to control insect damage and the use of herbicides to control herbacious growth competing with conifer seedlings. These activities are surely destined to further reduce the production of wildlife on forest lands.

We (Canadian Wildlife Federation) cannot accept the continuation of forest management policies which ignore other land based values. Therefore, the integration of forest and wildlife management policies must be introduced by all provinces as a priority action. Competent wildlife and fisheries biologists must be given a full opportunity to work in concert with foresters in the development and implementation of comprehensive management plans. Furthermore, adequate provision must be made to ensure that biological input goes into extension programs for application on private forested lands. Such programs must include provisions for the recovery, development and enhancement of important wetland areas as well as the techniques for improving forest land for wildlife.

Over the past twenty-five or more years, there has been a growing tendency to exclude the forest industry from an increasingly large area, designated as parks, preserves or other special areas. This has occurred largely by public demand, because of the industry's poor track record in respect of its operations on public lands. The rip and tear methods employed by the industry, which lay bare large tacts of land, without apparent efforts at rehabilitation, stiffens the public's resolve to ensure some areas will be protected from such carnage. Thus the industry is shut out of increasingly large areas which, in many instances, would benefit from the application of select sylvicultural techniques. The forest industry must assume a full measure of responsibility for this direct public reaction to its arrogance and lack of concern for other forest values.

For the future, the forest industry must be made fully aware of its responsibility for the management of forest lands in a manner which gives full recognition to all other forest based resources, including wildlife. This requirement must be made a condition of the forest operators' licence, and be recognized as part of the price the forest industry must pay for the privilege of harvesting wood from public lands. The deterioration of wildlife habitat, occurring 
as a consequence of forest extraction operations and management practices, is largely due to poor planning and lack of consideration for other values. Mitigating and remedial measures must become an integral part of forest operations. The knowledge and technology is available. It is now time to apply it as a normal procedure in the course of forest operations.

It is becoming evident, however, that the forest industry, in the process of it's analysis of the problem facing it, has not given other forest based resources proper consideration. The discussion paper, "A Forest Sector Strategy for Canada", sponsored by the Honourable John Roberts, makes only passing reference to environmental concerns and no direct acknowledgement to wildlife habitat requirements.

On the positive side, the 46th FederalProvincial Wildlife Conference held in Whitehorse, Yukon, June 1-4, has initiated plans to hold a symposium - "Integrated Forest and Wildlife Management", late in 1983. The plan would have foresters and wildlife managers, from government, industry and universities, prepare and present papers which would serve as the guidelines for future integration of forest and wildlife management, both in planning and implementation. The real test will come when forest industry executives and our political leaders are faced with the real ity of formulating policies and enacting legislation to give substance to the guidelines. Let's hope they are equal to the task.

\section{Silviculture and Forest Tree Management}

WG \#7 Business from Prince George, BC The Working Group held a 3-hour meeting together with the Entomology and Pathology WG on the use of chemicals in Forestry. Three speakers were invited to speak: Mr. Gary Lloyd from the Ministry of Forests in BC, Mr. Al Schwitzer from Dow Chemical Co, in Edmonton, Alberta and Mr. Frank Pendl, also of the Ministry of Forests of BC. Mr. Lloyd spoke on the arguments, often emotional and nonfactual, which were presented against the use of chemicals in forestry. Mr. Schwitzer talked on the difficulties and expenses of getting chemicals certified and that Canada has more stringent testing procedures for new chemicals than the USA. Procedures can take 4 to 6 years before new chemicals can be certified and it may take 2 years just to broaden certification from agriculture to forestry or to apply a chemical from the air rather than on the ground.
Mr. Pendl presented a discussion paper for a "Policy statement on the use of chemicals in forest management" to be presented to the national executive of the CIF.

Conclusions drawn from the three talks and a previous business meeting are:

1. WG \# 7 will attempt to include brief statements in The Forestry Chronicle on silvicultural practices across Canada. Dr. Roy Strang of the Forest Research Council of BC, volunteered to be the coordinator of this material and people from all major regions of Canada agreed to submit materials to $\mathrm{Dr}$. Strang.

2. The discussion paper presented by Frank Pendl needs some further work and when his committee has reviewed the matter, a finished statement will be sent to the National Executive of the CIF on behalf of Entomology and Pathology as well as Silviculture and Tree Improvement WG's. This statement will incorporate both herbicides and insecticides/fungicides under the term chemicals. The deadline of November 30 was set for completion of the finished statement.

A.K. Hellum Chairman

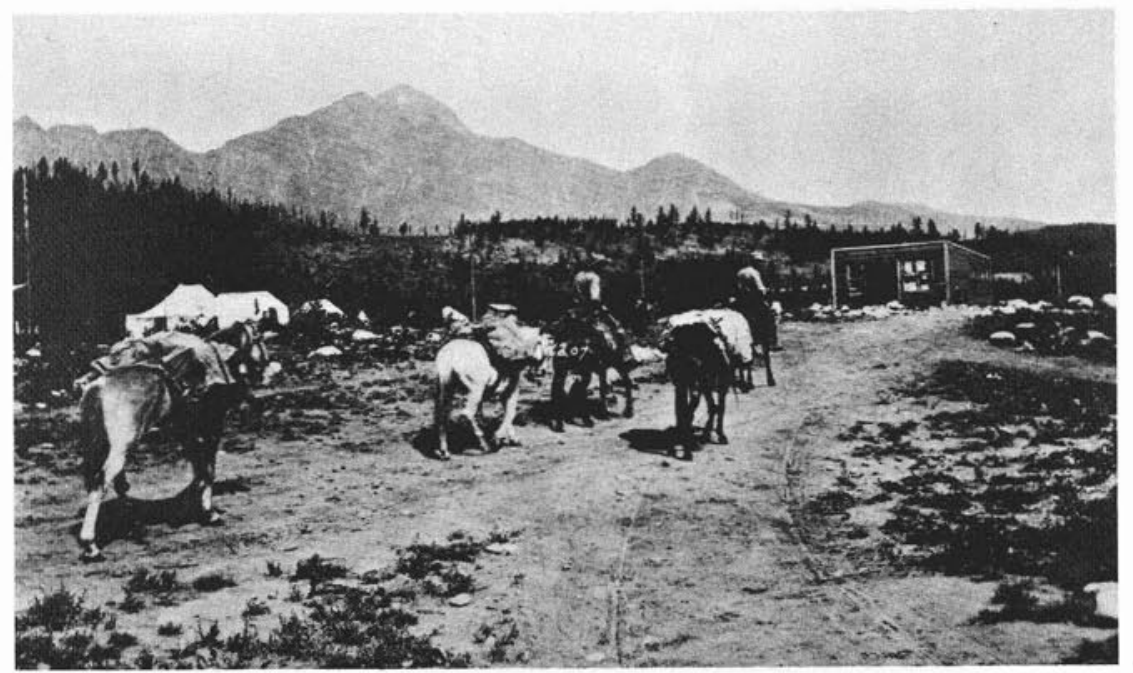

Forest survey crew and rangers leaving Jasper, Alberta, 1911 